University of Nebraska - Lincoln

DigitalCommons@University of Nebraska - Lincoln

Sociology Department, Faculty Publications

Sociology, Department of

2008

Gender Trajectories of Adolescent Depressed Mood: The Dynamic Role of Stressors and Resources

Christina D. Falci

University of Nebraska-Lincoln, cfalci2@unl.edu

Follow this and additional works at: https://digitalcommons.unl.edu/sociologyfacpub

Part of the Gender and Sexuality Commons, Medicine and Health Commons, and the Social

Psychology and Interaction Commons

Falci, Christina D., "Gender Trajectories of Adolescent Depressed Mood: The Dynamic Role of Stressors and Resources" (2008). Sociology Department, Faculty Publications. 190.

https://digitalcommons.unl.edu/sociologyfacpub/190

This Article is brought to you for free and open access by the Sociology, Department of at DigitalCommons@University of Nebraska - Lincoln. It has been accepted for inclusion in Sociology Department, Faculty Publications by an authorized administrator of DigitalCommons@University of Nebraska - Lincoln. 
Published in Stress Processes across the Life Course, ed. Heather A. Turner \& Scott Schieman, Advances in Life Course Research, Volume 13 (Amsterdam, etc.: Elsevier/JAI, 2008),

pp. 137-160.

Copyright ( 2008 by Elsevier Ltd. Used by permission.

\title{
Gender Trajectories of Adolescent Depressed Mood: The Dynamic Role of Stressors and Resources
}

\author{
Christina D. Falci
}

\begin{abstract}
This research examines how gender variation in the trajectory of stressors and resources during high school shapes gender variation in the trajectory of depressed mood. Boys have steeper gains in depressed mood than girls during high school. Adolescents with increasing levels of school or work strain and declining levels of parental support or mastery were more likely to have an increasing trajectory of depressed mood; the effect of chronic work was stronger for boys than girls. Steeper declines in parental support and gains in work strain among boys relative to girls explain boy's faster rate of increase in depressed mood during high school.
\end{abstract}

Roughly $30 \%$ of adolescents report moderate to severe depressive symptoms (Rushton, Forcier, \& Schectman, 2002) and levels of depressive symptoms appear to increase throughout adolescence (Ge, Conger, \& Elder, 2001). Depressed mood is an important public health concern. Depressive symptoms are the strongest predictor of suicidal ideation which, in turn, predicts suicide attempts (Kandel, Raveis, \& Davies, 1991). Sui- 
cide is the fourth leading cause of death among 10-14-year olds in the United States and the third leading cause of death among 15-24-year olds (Anderson, 2001). The presence of depressed mood in adolescence also has important life course consequences. The early occurrence of depression in adolescence sets a foundation for recurrent and severe depressive episodes later in life (Belsher \& Costello, 1988; Kovacs, Feinberg, CrouseNovak, Paulauskas, \& Finkelstein, 1984). Furthermore, as adolescents transition into adulthood, their parenting and work performance can be impeded by depression (Anderson, Kohler, \& Letiecq, 2005; Downey \& Coyne, 1990; Vredenburg, Krames, \& Flett, 1986). For these reasons it is important to know why, and for whom, levels of depressed mood tend to increase during adolescence.

Both adolescent girls and boys are likely to experience gains in depressed mood during adolescence (between the ages of 10 and 20); however, the rate of increase in depressed mood during adolescence and the timing of the increase in depressed mood within adolescence may vary by gender. Gender differences in adolescent depressive symptoms emerge around age 13, with adolescent girls reporting higher levels of depressive symptoms than boys (Ge et al., 2001; Wichstrøm, 1999). This gender difference emerges because the rate of growth in depressive symptoms increases at a faster rate among girls in early adolescence (between age 10 and 14) compared to boys. For adolescent boys, in contrast, significant gains in depressed mood appear to occur in later adolescence (beginning around age 14) rather than early adolescence (Ge et al., 2001). Thus, previous empirical research suggests that the timing of the increase in depressed mood may vary by gender, with girls experiencing their steepest gains in depressed mood during early adolescence and boys experiencing their steepest gains in later adolescence.

If this is true, we might expect girls to enter high school with higher levels of depressive symptoms but see a narrowing of the gender gap during the high school years. In other words, even if boys maintain lower levels of depressed mood throughout high school, the difference between girls and boys may decrease over time. Consistent with this idea, studies on young adults, i.e., beyond the high school years, suggest that the gender gap declines as adolescents transition into young adulthood (Galambos, Barker, \& Krahn, 2006; Needham, 2007). I expect the gender gap in depressed mood to decline during high school. This can only occur if the trajectory of depressed mood during high school varies by gender.

Using a longitudinal random sample of 766 white adolescents living in the Midwest the current research investigates how and why 
the magnitude of the gender gap in depressed mood changes during high school. To understand why the magnitude of the gender gap may change during this time, concepts from a life course perspective are incorporated into the stress process model of mental health and illness. Utilizing a longitudinal design, I conceptualize stressors and resources as dynamic developmental processes that shape the trajectory of depressed mood. This research will focus on three developmental properties in adolescence likely to influence the trajectory of depressed mood: parental support, chronic role strain and mastery. I expect gender differences in the trajectories of these stressors and resources during high school and gender variations in the effect of these stressors and resources on depressed mood to explain gender differences in the trajectory of depressed mood during high school.

\section{Dynamic Stressors and Resources In Adolescence}

The adolescent phase in the life course is likely to be characterized by a high level of developmental change or discontinuity. The shifting nature of social relationships with parents, an intense period of self-concept formation, and the expanding number of social roles adopted by adolescents should lead to considerable changes in psychosocial resources and stress exposure throughout adolescence. Moreover, these developmental changes are likely to vary by gender. There is limited empirical evidence as to how parental support, stress exposure and mastery change during adolescence, but there are compelling theoretical arguments to expect both discontinuity and gender variations in these factors during high school.

During adolescence, parental support is likely to decline (Buist, Deković, Meeus, \& van Aken, 2001; Polce-Lynch, Myers, Kliewer, \& Kilmartin, 2001). Parents and adolescents often have to negotiate an adolescent's desire for autonomy and independence from parents and parents' attempts to manage the pace of adolescent self-sufficiency (Steinberg, 1987). These negotiations can produce high levels of parentadolescent conflict (Arnett, 1999), which may coincide with declining closeness to parents (Larson \& Richards, 1991). Even without overt parent-adolescent conflict, parents may withdraw from their adolescents' lives in order to give them more autonomy, or adolescents may push their parents away to attain greater independence. Either circumstance could lead to the perception of declining social support from parents. These declines in parental support might occur more rapidly for adoles- 
cent boys compared to girls, since parents often expect more autonomy and independence from sons than daughters (Pomerantz \& Ruble, 1998). Adolescent boys might also be more inclined to push their parents away as they attempt to conform to masculinity norms (Chu, 2005).

Mastery is likely to increase during adolescence. Over the life course, perceived control follows a curvilinear pattern, with increasing levels in adolescence through young adulthood and declining levels in later life (Mirowsky \& Ross, 2007). On average, gains in mastery might occur because adolescents are given, or insist on, greater autonomy and independence from parents in carrying out their day-to-day lives (Ryan \& Lynch, 1989). Higher levels of autonomy and independence should correspond with increasing opportunities to engage in performance accomplishments, the primary route for developing self-efficacy (a concept similar to mastery) (Bandura, 1997). Indeed, longitudinal research on another related construct, locus of control, provides preliminary support for the hypothesis that mastery increases during high school (Chubb, Fertman, \& Ross, 1997).

The rate of increase in mastery, however, might be faster for boys relative to girls during high school. Parents tend to treat their sons and daughters differently (Raley \& Bianchi, 2006). Compared to daughters, mothers tend to give sons more freedom and independence, encourage sons to do things on their own, and attribute sons' accomplishments to positive internal qualities (Raley \& Bianchi, 2006; Pomerantz \& Ruble, 1998). These studies suggest that boys are given greater opportunity to develop high levels of mastery relative to girl, because boys will have more opportunities and encouragement to engage in successful performance accomplishments. If this is true, then levels of mastery should increase at a faster rate for boys than girls during high school. Cross-sectional research shows that adolescent boys tend to report higher levels of mastery than girls in high school (Bergman \& Scott, 2001; Marcotte, Alain, \& Gosselin, 1999).

Stress exposure is likely to increase during adolescence. Using an index of 25 undesirable life events, Ge, Lorenz, Conger, Elder, and Simons (1994) found that stressful life events increased between age 9 and 20 on a sample of adolescents living within intact families. The current study focuses on gains in chronic role strain. The number of social roles an adolescent occupies often expands during adolescence, which may increase the possibility of experiencing chronic role strain and/or role conflict. For example, as adolescents get older they are more likely to begin work for pay and possibly increase the intensity of work over time 
(Mortimer, Finch, Owens, \& Shanahan, 1990). At the same time, existing roles, such as that of student, may take on new meaning. As adolescents approach high school graduation, they often experience increasing pressure to be successful academically (Lee \& Larson, 2000). Therefore, chronic strain from the social roles of student and worker are likely to increase during high school.

There may also be gender variations in the trajectories of chronic strain during high school. Chronic work strain might increase at a faster rate for boys compared to girls during high school. Research suggests that the intensity of work (number of hours and stress exposure) increases more for boys than girls with each subsequent job in an adolescent's early work career (Mortimer et al., 1990). In contrast, chronic school strain might increase at a faster rate for girls. Girls are also more likely than boys to graduate from high school and enroll in college (NCES, 2007). These trends suggest the possibility that girls may put increasingly more academic pressure on themselves as they approach high school graduation compared to boys. Previous cross-sectional research using a Norwegian sample of adolescents found that girls experienced more school pressure than boys (Murberg \& Bru, 2004).

Overall, adolescence is likely to be a time of considerable discontinuity in stressors and resources and the developmental trajectories of stressors and resources may vary by gender during high school. Specifically, parental support might decline and work strain might increase faster for boys than girls. In contrast, school strain might increase at a faster rate and gains in mastery may not be as steep for girls compared to boys.

\section{Gender Differences in the Trajectory of Depressed Mood}

Developmental changes in stressors and resources should provide insight into the increasing levels of depressed mood during adolescence. Adolescents who experience gains in chronic role strain, fail to maintain socially supportive relationships with parents, and fail to develop high levels of mastery are likely to have an increasing trajectory of depressed mood during adolescence (Avison \& McAlpine, 1992; Cornwell, 2003; Lee \& Larson, 2000; Meadows, Brown, \& Elder, 2006; Mortimer, Harley, \& Staff, 2002; Wenz-Gross, Siperstein, Untch, \& Widaman, 1997). Since the develop- mental trajectories for parental support, mastery and chronic role strain are likely to vary by gender, discontinuity in resources and 
stressors should also provide insight into why the trajectory of depressed mood might vary by gender during high school.

Stress process researchers attempt to understand social status differences in health outcomes in two ways. First, the mean level of resources and stressors tend to vary across social status characteristics (Aneshensel, 1992; Pearlin, 1989). The social status group with higher levels of stressors and fewer resources will have higher levels of depressed mood (Turner \& Avison, 2003; Turner \& Lloyd, 1999). Among adolescents, gender differences in the self-concept, with adolescent boys reporting higher levels of self-esteem and self-efficacy, explains a substantial portion of the gender differences in depressive symptoms (Avison \& McAlpine, 1992). Gender differences in social support and stressful life events do little to explain lower levels of depressed mood among adolescent boys, because adolescent girls tend to report higher levels of social support and boys tend to report a higher number of stressful life events (Avison \& McAlpine, 1992; Meadows et al., 2006).

Second, the effect of stressors and resources on health outcomes can vary across social status characteristics (Aneshensel, 1992; Pearlin, 1989). The differential effects of resources or stressors on health outcomes can either exacerbate or fail to produce social status group differences in mental health outcomes. For example, the tendency for women to report more stressful life events happening to loved ones and for these network events to have a stronger impact on women's well-being exacerbates gender differences in depressive symptoms among adults (Kessler \& McLeod, 1984). Some research has found that, among adolescents, stressful life events have a stronger effect on depressive symptoms for girls than for boys (Ge et al., 1994; Meadows et al., 2006). It is unclear if similar findings will result when considering chronic role strain, which is a focus of the current research. Gender differences in the effects of chronic role strain on depressed mood may depend on the type of role stressor, such as work or school. Specifically, whether or not the role of student and worker are identity-relevant stressors for both boys and girls to the same degree (Thoits, 1991). If role identity salience or commitment to work or school varies by gender, then we would expect the effect of chronic work and school strain on depressed mood to vary by gender, respectively. Role strains connected to role identities with higher salience or commitment tend to exacerbate the ill effects of role strain on well-being (Marcussen, Ritter, \& Safron, 2004).

The effect of resources, such as parental support and mastery, on depressed mood may also vary by gender. Previous research finds that mother support has a stronger effect on depressed mood among adoles- 
cent girls than boys (Avison \& McAlpine, 1992; Meadows et al., 2006). Self- esteem has been shown to have a stronger effect on adolescent girls' depressive symptoms than boys (Bolognini, Plancherel, Bettschart, \& Halfon, 1996). An analogous gender difference may occur for the effect of mastery on depressed mood. The current study will explore gender variation in the effect of chronic role strain, parental support and mastery on depressed mood.

The current study adds a third important social status group comparison. I assess how the growth rate of stressors and resources vary by gender. It is gender differences in the growth rate of stressors and resources during high school that will lead to the augmentation of or reduction in the gender gap for depressed mood during high school. It is important to distinguish between group differences in means and group differences in the growth rate because the rank order of group differences can stay the same over time even though the magnitude of the social status gap might change. For example, it is hypothesized that adolescent boys will consistently report lower levels of depressed mood each year in high school than girls, but the magnitude of the gender gap will reduce because depressed mood will increase at a faster rate among adolescent boys than girls during high school. It is also important to distinguish between mean level differences and differences in the growth rate because mean level differences in stressors and resources can explain gender variation in depressed mood at one point in time, but variation in the growth rate will explain why gender variation in depressed mood changes over time.

Gender variation in the growth rate of stressors and resources could help explain why the gender gap declines during high school. If, as hypothesized, adolescent boys experience greater increases in work strain and greater declines in parental support than girls, then accounting for this variation should reduce gender differences in the trajectory of depressed mood during high school (Cornwell, 2003; Ge et al., 1994). At the same time, if, as hypothesized, adolescent boys experience steeper gains in mastery and less steep gains in school strain relative to girls, then this should correspond with less steep gains in depressed mood for adolescent boys relative to girls. Accounting for this variation may increase gender differences in the trajectory of depressed mood during high school. Thus, controlling for gender variation in the trajectories for chronic strain, parental support and mastery could both reduce and augment gender differences in depressed mood during high school.

Overall, then, hypothesized gender variations in the trajectories of stressors and resources do not privilege one gender over the other. In 
some instances, adolescent girls may have more advantaged resources (e.g., parental support) and less disadvantageous stressors (e.g., work strain). In other instances, adolescent boys may have more advantaged resources (e.g., mastery) and less disadvantageous stressors (e.g., school strain). For this reason it is important to take into account a variety of stressors and resources to understand how and why the trajectory of depressed mood differs by gender during high school. At the same time, the extent to which these hypothesized gender variations in developmental trajectories alter the gender differences in the trajectory of depressed mood will depend on gender variation in the effect of these stressors and resources on depressed mood.

\section{Methods}

\section{Sample}

The Youth Development Study (YDS) is a longitudinal random sample of adolescents from a large city in the Midwest. Census data indicates that this sample is similar to the US population with respect to social and economic indicators (Mortimer, 2003). In 1988, 849 white adolescents in the 9 th grade participated in the first wave of data collection. The present study only uses information from white adolescents for the following reasons. First, the Hmong respondents $(N=129)$ do not interpret the survey questions on mastery and depressed mood in a manner consistent with the nonHmong sample (Dunnigan, McNall, \& Mortimer, 1993). Second, the number of Latino $(N=45)$ and black $(N=78)$ participants in this sample is too low to draw sound substantive conclusions. This research uses the first four waves of data from the YDS collected each year in high school. The subjects' parents also filled out questionnaires in waves one and four. There is information from at least one parent for $96 \%$ of the sample.

The final analytic sample contains 776 adolescents with sufficient data for the multivariate growth curve models. An advantage of growth curve modeling is the ability to keep participants in the sample who do not have data at every wave or who have missing data on some indicators. The vast majority of respondents in the final sample have three or four complete waves of data 93\% (694 out of 776). Eighty-two cases have only two complete waves of data. Respondents with less than two complete waves of data were dropped from the sample. Adolescents with lower background socioeconomic status (SES) were more likely to attrite from the study, however, there is no evidence that sample attrition has biased the results of this research. The means for the wave one variables did not 
significantly differ between attriters and nonattriters, and baseline crosssectional associations did not differ between the full sample (attriters and nonattriters) and nonattriters (Ahern \& Le Brocque, 2005; Fitzgerald, Gottschalk, \& Moffit, 1998). Finally, a predicted probability of remaining in the sample did not significantly predict the growth rate of depressed mood.

\section{Measures}

Depressed Mood. Depressed mood is measured using three items from the "General Well-Being Scale" of the Current Health Insurance Study Mental Health Battery (Ware, Johnson, Davis-Avery, \& Brook, 1979). The respondents were asked three questions on how often during the past month they have felt depressed, been low in spirits or felt downhearted. The response choices ranged from not at all (coded 1) to all of the time (coded 5). The index was created by summing the three items. The values of the index range from 1 to 13 with higher values indicating more depressed mood. Factor and reliability analysis indicate a unidimensional index with good reliability (Cronbach's $\alpha=.84$ or above across all four time points).

Mastery. The mastery index pertains primarily to feelings representing a lack of control (Pearlin \& Schooler, 1978). The five indicators for mastery are: I feel I am being pushed around in life, I have little control over the things that happen to me, I often feel helpless in dealing with problems in life, there is little I can do to change many of the important things in my life and there is really no way I can solve some of the problems I have. The response choices for all of these items ranged from strongly disagree (coded 1) to strongly agree (coded 4). All five items were reverse coded when constructing the index. The mastery index was created by summing the five items. The index ranges from 1 to 16, with higher values indicating higher mastery. Factor and reliability analysis indicate a unidimensional index with good reliability (Cronbach's $\alpha=.70$ or above across all four time points).

Parental Support. Parental support was measured separately for mothers and fathers using identical survey questions. Waves one through four of the YDS have parental support information up to four parental figures: residential fathers, residential mothers, nonresidential fathers and nonresidential mothers. For each parent, adolescents were asked how much they wanted to be like their parent, how close they felt, how often their parent talked over important decisions with them, how often their parent listened to their side of an argument, and how often they talked over personal concerns and decisions with their parent. Each 
question had four response categories, but the response content varied by question (a lot to not at all, extremely close to not close at all or never to often). Since the response choices varied, all items were standardized prior to creating indices. Parental support indices were created for each type of parent-adolescent relationship, with higher values indicating more parental support. Factor analyses and Cronbach's $\alpha$ showed that the five items in the parental support indices created single factor and reliable indices $(\mathrm{a}=.80$ or above across all types of parent-child relationships for all four time points). These four indices were then used to create two final measures of parental support, one for mother support and the second for father support.

The following decision rules created the two final measures of parent support. If the respondent reported on support from a residential mother and/or father, then the residential mother and/or father support indices, respectively, are used as the parent support measures, regardless of the kinship relationship between the parent and adolescent. If adolescents did not have a residential mother or father, then the nonresidential mother or father support measure, respectively, are used as the parental support measures. The quality of residential parent-adolescent relations is given precedence in the parental support measures, because residential parents are more likely to exert a greater influence on adolescent outcomes than nonresidential parents (Falci, 2006). Information on the kinship tie, such as biological or stepparent, in combination with residential status was used to assure consistency of reporting on each parental figure across all four waves of data.

Chronic Strain. Chronic strain is measured in two life domains: school and work. School strain is measured by asking adolescents the following question: how often are there time pressures when you do your school work? Response choices ranged from never (coded 1) to almost always (coded 5). Work strain is measured using an eight-item index: time pressure at work, exposure to noxious work conditions, having too much work, having to work very hard, feeling drained after work, lack of clarity on job responsibilities, responsibilities for things outside of one's control and having to upset others to satisfy some people on the job. Again, the response choices varied; therefore, all items were standardized prior to creating the index. The work strain index is the sum of the eight items, with higher values indicating greater work strain. Factor and reliability analysis indicate a unidimensional index with good reliability (Cronbach's $\alpha=.70$ or above across all four time points). 
The goal of the chronic strain measures is to assess the level of chronic strain experienced by the adolescent from each social role. Although all adolescents should be attending school, 77 respondents dropped out of school somewhere between the 9th and 12th grade. Adolescents who dropped out of school were given the value of zero on the school strain measure. As might be expected, not all adolescents were employed. In this sample, roughly $12 \%$ of adolescents never reported working and $24 \%$ always reported working at the time of survey administration. The remaining and $74 \%$ reported working in some but not all years of high school at the time of survey administration; among the on-again off-again workers, over half reported working at three or four time points. Since adolescents who are not working cannot experience work strain, adolescents who are unemployed are given the lowest value on the work strain index for the relevant year in high school. In all multivariate analyses with each of the chronic strain measures, time-varying dummy variables are entered into the model indicating whether the adolescent is currently not in school (equals 1 ) or not working (equals 1 ) at the time of survey administration.

Gender and Social Class. The two social status characteristics in this study are gender and social class. Gender is a dummy variable with boy $=$ 1. The parent survey of the YDS had information on the SES for the family of origin. Following House et al. (1990), SES of origin is measured by a composite of parental income and education gathered in the first year of data collection. Parental income was determined by the fathers' report of family income. If the father's report was not available, then the mother's report was used. Parental education was determined by averaging the reported education of the two parents in the household, or by the education of the sole parent. Background SES is created by summing the Z-scores for household income and parents' education. Since social class is not a focal part of this analysis, missing values on this variable are replaced with the mean $(N=27)$.

\section{Data Analysis}

Growth curve models are used to investigate within and between person changes in parental support, chronic strain, mastery and depressed mood during high school. Growth curve analysis identifies a unique intercept and slope (or growth rate) for each respondent. In this study, the intercept is represented at two different time points. Initial status identifies the mean of the dependent variable in the first wave (9th grade), and final status identifies the mean of the dependent variable in the last wave 
(12th grade). The growth rate represents the expected change in the dependent variable across each wave of data collection. All models are estimated using PROC MIXED in SAS with an unstructured specification for the variance-covariance structure (Singer, 1998). The time-varying independent variables are included as fixed effects. Time-varying independent variables are group-mean centered and the grand-mean centered group means are included in the level-2 equation for the intercept. In so doing, I assess the effect of within- person change in the time-varying independent variable on change in the dependent variable (Homey, Osgood, \& Marshall, 1995). For ease of interpretation, I do not report the coefficients for the grand-mean centered group means in the tables.

\section{Results}

\section{Change in Chronic Strain, Parental Support and Mastery}

This phase of the analysis will investigate how the trajectories for chronic strain, parental support and mastery vary by gender during high school. This will lay the foundation for understanding why the trajectory of depressed mood might vary by gender. All models in Table 1 report on the initial status (mean in the 9th grade), the growth rate (expected yearly change) and the final status (mean in the 12th grade) for two sources of chronic strain, two sources of parental support and mastery. The growth rate and intercepts are allowed to vary by gender. Girls are the omitted reference group; therefore, the coefficients for initial status, the growth rate and final status represent the effect for girls. The coefficients for boys represent the numerical mean difference in initial status, the growth rate or final status for boys from the effect for girls. All models also control for social class; although the coefficients are not reported in the table. The mean for the social class variable is equal to zero; therefore, the intercepts and slope reported in the table represent the effect of gender holding social class constant at the mean. The random effects portion of Table 1 reports the variance component for initial status, the growth rate and the level-1 error. Significant variance components for initial status and the growth rate indicate that there is significant individual variation in initial status and the growth rate, respectively, across the sample.

Models 1 and 2 in Table 1 evaluate changes in chronic role strain during high school from school and work by gender. School strain increases over time for both adolescent girls and boys $(\beta=.064, p<.01)$. There are no gender differences in the mean or rate of growth in school strain. In 


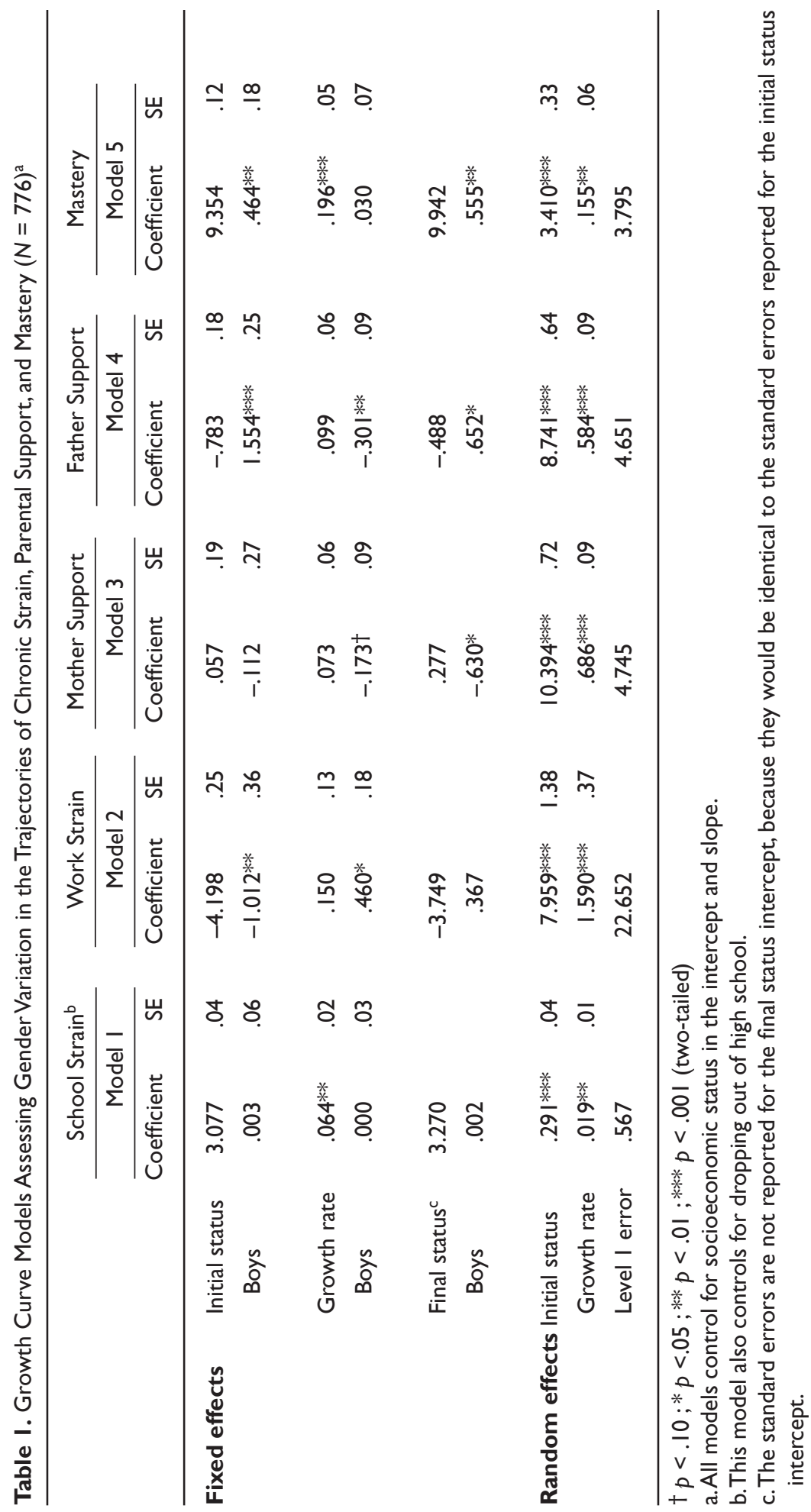


contrast, work strain is lower among adolescent boys in the 9th grade $(\beta$ $=-1.012, p<.01)$ than girls. This gender difference in the mean in the 9th grade occurs because adolescent girls are more likely to be working in the 9th grade than boys. In analyses not shown on a sub-sample of respondents who were working at three or more time points $(N=356)$, adolescent boys reported significantly higher levels of chronic work strain in the 9th grade. Among consistent workers, then, boys report higher levels of chronic strain than girls.

The rate of growth in work strain also varies by gender, with boys experiencing a significantly faster rate of growth in work strain throughout high school $(\beta=.460, p<.05)$ compared to girls. For girls, chronic work strain does not significantly increase during high school $(\beta=.150, \mathrm{~ns})$. Part of this faster rate of increase in work strain occurs because adolescent boys are significantly more likely to enter the work force over time during high school than girls. At the same time, in analysis not shown on the same sub- sample of workers, chronic strain increased at a faster rate for boys than girls, and girls, on average, did not experience gains in work strain during high school among workers. Clearly, levels of work strain are increasing at a faster rate for boys than girls.

Models 3 and 4 in Table 1 investigate changes in parental support during high school from mothers and fathers. On average, levels of mother and father support do not significantly change among adolescent girls $(\beta$ $=.073$, ns and $\beta=.099, \mathrm{~ns})$ during high school. The growth rate for father support significantly varies by gender $(\beta=-.301, p<.01)$. An analysis not shown, with boys as the omitted reference group for gender, indicates that adolescent boys experience significant declines in father support during high school $(\beta=-.202, p<.01)$. There is a tendency toward a similar gender difference in the growth rate of mother support $(\beta=-.173, p$ $<.10)$. In fact, this slight gender variation in the growth rate for mother support leads to the emergence of significant gender difference in mother support by the 12 th grade $(\beta=-.630, p<.05)$, with girls reporting more support from mothers than boys. Gender differences in mother support were not present in the 9 th grade $(\beta=-.112, \mathrm{~ns})$. Gender differences in the growth rate of father support substantially reduces gender differences in father support between the 9th and 12th grade (from 1.554 to .652), although boys still report higher levels of father support in both 9th and 12th grade.

Model 5 in Table 1 investigates changes in mastery during high school. Overall, adolescents experience significant gains in mastery during high school $(\beta=.196, p<.001)$. The growth rate for mastery does not significantly vary by gender $(\beta=.030, \mathrm{~ns})$. Adolescent boys, however, report 
higher levels of mastery in both the 9th and 12th grade than girls $(\beta=.464$, $p<.01$ and $\beta=.555, p<.01)$. The emergence of gender differences in mastery appears to occur before the 9 th grade.

This gender variation in the trajectories of stressors and resources should help us understand gender variation in the trajectory of depressed mood. Adolescent boys are at a disadvantage relative to girls with regard to parental support and work strain. Steeper declines in parental support and steeper gains in work strain may lead to a faster rate of growth in depressed mood among boys during high school compared to girls. Since there was no gender differences in the growth rate for school strain or mastery, school strain and mastery are unlikely to differentially shape the trajectory of depressed mood by gender. These predictions, however, may not hold if the effect of these resources and stressors on depressed mood varies by gender.

Gender variation in the mean level of these stressors and resources should also help explain gender variation in the mean differences for depressed mood at each wave. In the 12th grade, for example, adolescent boys report closer relations to their fathers and a higher level of mastery compared to girls. These advantages could mediate mean gender differences in depressed mood in the 12th grade. However, boys also report higher levels of work strain and less support from their mothers. Controlling for these disadvantages among boys could enhance mean level gender differences in depressed mood in the 12th grade.

\section{Trajectories of Depressed Mood}

The first model in Table 2 investigates how the trajectory of depressed mood may differ by gender. Subsequent models assess how changes in parental support, chronic strain and mastery shape the trajectory of depressed mood and the gender variation therein. The rate of growth in depressed mood differs for boys and girls $(\beta=.176, p<.05)$. On average, adolescent girls do not experience significant gains in depressed mood during high school $(\beta=-.028, \mathrm{~ns})$. However, an analysis with boys as the omitted reference group for gender (not shown), indicates that adolescent boys experience significant gains in depressed mood during high school $(\beta=.147, p<.01)$. Although these contrasting trajectories lead to a $52 \%$ reduction of the gender gap in depressed mood between 9th and 12th grade, adolescent boys still report lower levels of depressed mood at both time periods $(\beta=-1.022, p<.001$ and $\beta=-.495, p<.01)$. It is noteworthy that gender differences are reduced because adolescent boys experience steeper gains in depressed mood relative to girls, not because of declines in symptoms among girls. 


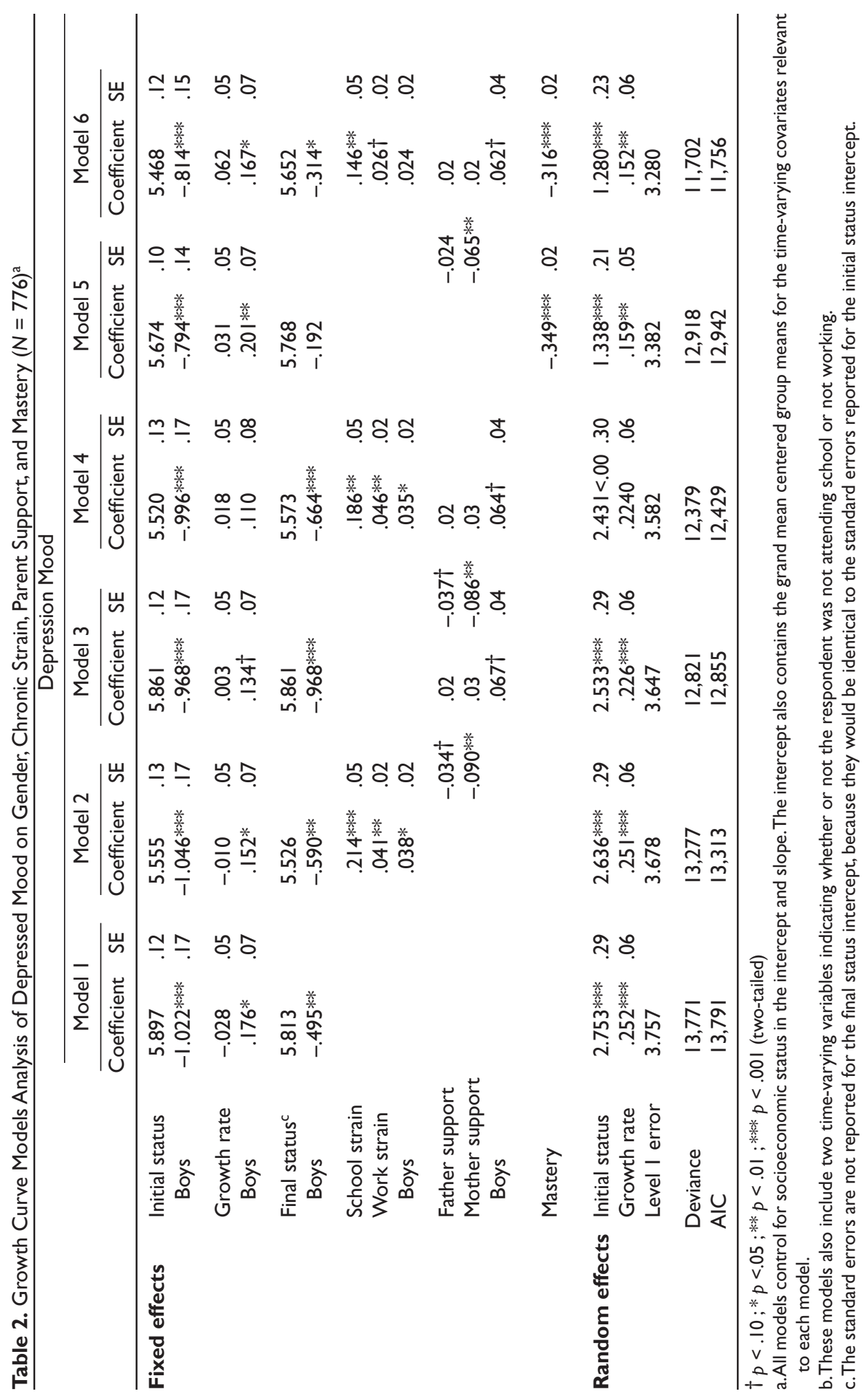


Models 2 through 4 include time-varying covariates for parent support and chronic strain. All of these stressors and resources play a significant role of shaping the trajectory of depressed mood during high school and alter the gender differences in the trajectory of depressed mood. Model two shows that gains in school strain are associated with a faster rate of growth in depressed mood $(\beta=.214, p<.001)$. In analyses not shown, the effect of school strain did not vary by gender. Gains in work strain are also associated with a faster rate of growth in depressed mood $(\beta=.041, p<.01)$, although the effect is stronger for adolescent boys ( $\beta$ $=.038, p<.05)$. This gender difference in the effect of work strain on depressed mood was replicated in analysis (not shown) on the sub-group of workers. Model three shows that declines in parental support are associated with an increasing trajectory of depressed mood $(\beta=-.034, p<.10$, and $\beta=-.090, p<.01)$. In analysis not shown, the effect of father support reached conventional levels of statistical significance when mother support was not included in the model $(\beta=-.049, p<.01)$. Finally, there is a tendency for the effect of mother support to be stronger for girls than boys $(\beta=.067, p<.10)$. In analyses not shown, the effect of father support did not vary by gender.

Model four includes both parental support and chronic stain in the model. The combination of controlling for chronic strain and parent support mediates the gender differences in the growth rate of depressed mood $(\beta=.110, \mathrm{~ns})$. Thus, adolescent boys experience steeper inclines in depressed mood relative to girls during high school for two reasons. First, levels of parental support decline at a faster rate for boys compared to girls. Second, levels of work strain increase at a faster rate and work strain has a stronger positive effect on depressed mood for boys compared to girls. Although these gender differences in chronic strain and parental support trajectories explain gender differences in the rate of change in depressed mood over time, gender differences in mean levels of chronic strain and parental support do not mediate the gender difference in levels of depressed mood in the 9th or 12th grade $(\beta=-.996, p<.001$, and $\beta=$ $-.664, p<.001)$. Boys consistently report lower levels of depressed mood, even when controlling for chronic strain and parental support.

Model 5 investigates the association between changes in mastery and the trajectory of depressed mood. Gains in mastery during high school are associated with less steep increases in depressed mood $(\beta=-.349$, $p<.001)$. In analysis not shown, this effect did not vary by gender. Controlling for mastery does alter the gender differences in the trajectory of depressed mood during high school. Gender differences in the growth rate of depressed mood during high school increase from $\beta=.176$, 
$p<.05$ in Model 1 to $\beta=.201, p<.01$ in Model 5. This is surprising because the trajectory of mastery did not significantly vary by gender during high school. Yet, the direction of the association was for boys to increase in mastery at a slightly faster rate than girls, and the effect of mastery on depressed mood is quite strong resulting in meaningful mean differences over time. If adolescent boys did not have a slightly more advantageous growth rate in mastery, then the gender differences in the trajectory in depressed mood would be even larger. The slightly faster rate of growth in mastery and the higher mean levels of mastery among boys compared to girls, fully mediates mean level gender differences in depressed mood by the 12th grade ( $\beta=-.192$, ns). Upon controlling for mastery, boys fully catch up to the higher levels of depressed mood among adolescent girls by the 12 th grade.

The final model in Table 2 shows the effect of all stressors and resources on depressed mood. Stressors and resources in adolescence explain a substantial portion of the variance in the trajectory of depressed mood. An estimate of the R2 is attained by calculating the reduction in the variance component for the growth rate across nested models (Raudenbush \& Bryk, 2002). Almost $40 \%$ of the growth rate in depressed mood during high school is explained by changes in chronic strain, mother support and mastery during high school [(.252 - .152)/.252 = .397], and changes in mastery during high school account for the largest part of this percentage $[(.252-.159) / .252=.369]$. It is likely, however, that chronic strain and parental support have an indirect effect on the trajectory of depressed mood through mastery development. Upon controlling for mastery in Model 6, the effect of parental support and chronic strain are reduced. A final set of additional analyses (not shown) tested for interactions between chronic strain and both parental support and mastery but found no significant effects. In other words, parental support and mastery did not buffer the effect of chronic strain on depressed mood.

\section{Discussion and Conclusion}

The current research investigated how and why the magnitude of the gender gap in depressed mood changed during high school. The magnitude of the gender gap in depressed mood during high school was reduced by $52 \%$ between the 9th and 12th grade. Unfortunately, the gender differences in depressed mood during high school did not reduce because levels of depressed mood declined among adolescent girls. Instead, levels of depressed mood increased at a faster rate for boys, allowing boys 
to approach the higher levels of depressed mood among girls. Although the gender gap is reduced, boys still report significantly lower levels of depressed mood compared to girls throughout high school. Thus, adolescent boys do not completely catch up to the higher levels of depressed mood experienced by girls in high school. Mastery appears to be an important factor in maintaining boys' mental health advantage. When mastery is controlled, adolescent boys do fully catch up to the higher levels of depressed mood among adolescent girls. The fact that adolescent boys have a slightly steeper rate of growth in mastery and significantly higher levels of mastery during high school compared to girls prevents them from having an even steeper rate of growth in depressed mood during high school relative to girls.

Clearly, adolescence is a risk period for developing depressed mood for both boys and girls. Although the current study did not investigate adolescents in early adolescence, the findings do suggest that the timing of the increase in depressed mood during adolescence might vary by gender. Adolescent girls are likely to experience the steepest gains in early adolescence; whereas, boys may experience their steepest gains in later adolescence (Ge et al., 2001; Wichstrøm, 1999). The findings from the current study do show that boys have a steeper gain in depressed mood relative to girls in later adolescence. At the same time, the gains in depressed mood made by adolescent girls in early adolescence might be larger than the gains in depressed mood made by boys in later adolescence, because adolescent girls consistently report higher levels of depressed mood throughout adolescence. Thus, the rank order of gender differences in depressed mood is preserved even if the magnitude of the gender gap is reduced in later adolescence.

The reasons for the increases in depressed mood during adolescence probably also vary by gender. Previous research suggests that self-concept development and body image play a substantial role in understanding why adolescent girls experience high levels of depressed mood in early adolescence (Siegel, Yancey, Aneshensel, \& Schuler, 1999). The data from the current research suggest that adolescent boys experience gains in depressed mood in later adolescence because they experience steeper gains in chronic work strain and steeper declines in parental support during high school than girls. Controlling for these gender differences in chronic strain and parental support fully explained the faster rate of growth in depressed mood among boys in high school relative to girls. This, of course, also explains why the gender gap in depressed mood is reduced during high school.

This research has expanded on previous research by investigating chronic role strain from school and work. Previous research among adoles- 
cents has focused on stressors in the form of stressful life events (Ge et al., 1994; Meadows et al., 2006; Joyner \& Urdy, 2000), finding that adolescent girls have higher levels of vulnerability to these stressors than boys. The current study found that the effect of school strain did not vary by gender, but adolescent boys are more vulnerable to chronic work strain than girls. Furthermore, boys are also much more likely to experience chronic work strain than girls. These gender differences played a large role in explaining why adolescent boys experienced steeper gains in depressed mood than girls in high school. It will be important for future research to continue to investigate different kinds of stress exposure in adolescence.

Since the timing of and reasons for the increase in depressed mood during adolescence appear to differ by gender, it will be necessary to address a wide array of issues throughout adolescence to ameliorate gender differences in depressed mood. Adolescent girls may be most at risk due to poor self- concept formation processes in early adolescence, whereas boys are most at risk due to gains in work strain and declines in parental support in later adolescence. Nevertheless, improving self-concepts, reducing chronic strain and promoting parent-adolescents relationships will prevent the development of depressed mood for both adolescent girls and boys. In fact, to rectify gender differences in depressed mood it will be necessary to address all of these factors. If, for example, we improve girl's self-concepts without improving levels of work strain and parental support for boys, then we might simply reverse the gender gap in depressed mood.

This current study highlights the utility of integrating a life course orientation into the stress process model and future research should consider two research strategies used within this research. First, conceptualize stressors and resources as dynamic developmental processes in adolescence. There is a considerable amount of discontinuity in stressors and resources during adolescence and the nature of this developmental change varies by gender. Second, investigate how the magnitude of social status gaps in mental health outcomes change over time. Boys consistently reported lower levels of depressed mood during high school. If this study did not investigate how gender differences in depressed mood changed over time, then it would have failed to recognize the greater increases in depressed mood among adolescent boys relative to girls in late adolescence.

Future research should also investigate the ways that chronic role strain and parental support shape the development of mastery during high school. Mastery appears to be an important mediator in the stress process among adolescents. Adolescence is a time of mastery develop- 
ment. Importantly, the level of mastery attained in adolescence will set the foundation for this critical personal resource in adulthood (Gecas, 1989; Pearlin, Nguyen, Schieman, \& Milkie, 2007). Anything that hinders or diminishes the development of mastery in adolescence, such as stress exposure or declines in parental support, may in turn lead to higher levels of depressed mood into adulthood. Indeed, in the current study, mastery had the largest and most direct influence on the trajectory of depressed mood during high school.

Finally, future research would also benefit from following individuals from early adolescence to late adolescence to investigate the claims that both the timing of increases in depressed mood and the reasons for the increases in depressed mood during adolescence vary by gender. This research finds that in late adolescence boys are more likely to experience gains in depressed mood compared to girls because they have fewer social resources from parents and greater chronic strain from work.

\section{Acknowledgments}

This research is supported by a grant titled "Work Experience and Mental Health: A Panel Study of Youth" from the National Institute of Child Health and Human Development (HD44138). The study was previously supported by the National Institute of Mental Health (MH42843). The author thanks Jeylan Mortimer, Ross Macmillan, Heather Turner, and Scott Schieman for helpful feedback and suggestions.

\section{References}

Ahern, K., \& Le Brocque, R. (2005). Methodological issues in the effects of attrition: Simple solutions for social scientists. Field Methods, 17, 53-69.

Anderson, E. A., Kohler, J. K., \& Letiecq, B. L. (2005). Predictors of depression among low-income, non-residential fathers. Journal of Family Issues, 26, 547-567.

Anderson, R. (2001). Deaths leading causes for 1999. National Vital Statistics Report, Vol. 49. Hyattsville, MD: National Center for Health Statistics.

Aneshensel, C. S. (1992). Social stress: Theory and research. Annual Review of Sociology, 18, 15-38.

Arnett, J. J. (1999). Adolescent storm and stress, reconsidered. American Psychologist, $54,317-326$.

Avison, W. R., \& McAlpine, D. D. (1992). Gender differences in symptoms of depression among adolescents. Journal of Health and Social Behavior, 33, 77-96.

Bandura, A. (1997). Self-efficacy: The exercise of control. New York: W.H. Freeman. 
Belsher, G., \& Costello, C. G. (1988). Relapse after recovery from unipolar depression: A critical review. Psychological Bulletin, 104, 84-96.

Bergman, M., \& Scott, J. (2001). Young adolescents' wellbeing and health-risk behaviors: Gender and socio-economic differences. Journal of Adolescence, 24, 183-197.

Bolognini, M., Plancherel, B., Bettschart, W., \& Halfon, 0. (1996). Self-esteem and mental health in early adolescence: Development and gender differences. Journal of Adolescence, 19, 233-245.

Buist, K. L., Deković, M., Meeus, W., \& van Aken, M. A. G. (2001). Developmental patterns in adolescent attachment to mother, father and sibling. Journal of Youth and Adolescence, 31, 167-176.

Chu, J. Y. (2005). Adolescent boys' friendships and peer group culture. New Directions for Child and Adolescent Development, 107, 7-22.

Chubb, N. H., Fertman, C. I., \& Ross, J. L. (1997). Adolescent self-esteem and locus of control: A longitudinal study of gender and age differences. Adolescence, 32, 113-129.

Cornwell, B. (2003). The dynamic properties of social support: Decay, growth, and staticity, and their effects on adolescent depression. Social Forces, 81, 953-978.

Downey, G., \& Coyne, J. C. (1990). Children of depressed parents: An integrative review. Psychological Bulletin, 108, 50-76.

Dunnigan, T., McNall, M., \& Mortimer, J. T. (1993). The problem of metaphorical nonequivalence in cross-cultural survey research: Comparing the mental health statuses of Hmong refugee and general population adolescents. Journal of Cross-Cultural Psychology, 24, 344-365.

Falci, C. (2006). Family structure, closeness to residential and nonresidential parents, and psychological distress in early and middle adolescence. The Sociological Quarterly, 47, 123-146.

Fitzgerald, J., Gottschalk, P., \& Moffit, R. (1998). An analysis of sample attrition in panel data: The Michigan study of income dynamics. The Journal of Human Resources, 33, 251-299.

Galambos, N. L., Barker, E. T., \& Krahn, H. J. (2006). Depression, self-esteem, and anger in emerging adulthood: Seven-year trajectories. Developmental Psychology, 42, 350-365.

Ge, X., Conger, R. D., \& Elder, G. H., Jr. (2001). Pubertal transition, stressful life events, and the emergence of gender differences in adolescent depressive symptoms. Developmental Psychology, 37, 404-417.

Ge, X., Lorenz, F. O., Conger, R. D., Elder, G., \& Simons, R. (1994). Trajectories of stressful life events and depressive symptoms during adolescence. Developmental Psychology, 30, 467-483.

Gecas, V. (1989). The social psychology of self-efficacy. Annual Review of Sociology, 15, 291-316.

Horney, J., Osgood, D. W., \& Marshall, I. H. (1995). Criminal careers in the short-term: Intra-individual variability in crime and its relation to local life circumstances. American Sociological Review, 60, 655-673.

House, J. S., Kessler, R. C., Herzog, A. R., Mero, R. P., Kinney, A. M., \& Breslow, M. J. (1990). Age, socioeconomic status, and health. The Milbank Quarterly, 68, 383-411. 
Joyner, K., \& Urdy, J. R. (2000). You don't bring me anything but down: Adolescent romance and depression. Journal of Health and Social Behavior, 41, 369-391.

Kandel, N. J., Raveis, V. H., \& Davies, M. (1991). Suicidal ideation in adolescence: Depression and, substance use and other risk factors. Journal of Youth and Adolescence, 20, 289-309.

Kessler, R. C., \& McLeod, J. D. (1984). Sex differences in vulnerability to undesirable life events. American Sociological Review, 49, 620-631.

Kovacs, M., Feinberg, T. L., Crouse-Novak, M. A., Paulauskas, S. L., \& Finkelstein, R. (1984). Depressive disorders in childhood: A longitudinal prospective study of characteristics and recovery. Archives of General Psychology, 41, 219-239.

Larson, R., \& Richards, M. H. (1991). Daily companionship in late childhood and early adolescence: Changing developmental contexts. Child Development, 62, 284-300.

Lee, M., \& Larson, R. (2000). The Korean "examination hell”: Long hours of studying, distress, and depression. Journal of Youth and Adolescence, 29, 249-272.

Marcotte, D., Alain, M., \& Gosselin, M. J. (1999). Gender differences in adolescent depression: Gender-typed characteristics or problem-solving skills deficits?. Sex Roles, 41, 31-48.

Marcussen, K., Ritter, C., \& Safron, D. J. (2004). The role of identity salience and commitment in the stress process. Sociological Perspectives, 47, 289-312.

Meadows, S. 0., Brown, J. S., \& Elder, G. H., Jr. (2006). Depressive symptoms, stress, and support: Gendered trajectories from adolescence to young adulthood. Journal of Youth and Adolescence, 35, 93-103.

Mirowsky, J., \& Ross, C. (2007). Life course trajectories of perceived control and their relationship to education. American Journal of Sociology, 112, 1339-13382.

Mortimer, J. T. (2003). Working and growing up in America. Cambridge, MA: Harvard University Press.

Mortimer, J. T., Finch, M. D., Owens, T. J., \& Shanahan, M. (1990). Gender and work in adolescence. Youth and Society, 22, 201-224.

Mortimer, J. T., Harley, C., \& Staff, J. (2002). The quality of work and youth mental health. Work and Occupations, 29, 166-197.

Murberg, T. A., \& Bru, E. (2004). School-related stress and psychosomatic symptoms among Norwegian adolescents. School Psychology International, 25, 317-332.

National Center for Education Statistics. (NCES). Digest of Education Statistics 2006. Accessed on January 2007. Available at http://nces.ed.gov/annuals

Needham, B. L. (2007). Gender differences in trajectories of depressive symptomatology and substance use during the transition from adolescence to young adulthood. Social Science and Medicine, 65, 1166-1179.

Pearlin, L. I. (1989). The sociological study of stress. Journal of Health and Social Behavior, 30, 241-256.

Pearlin, L. I., Nguyen, K. B., Schieman, S., \& Milkie, M. A. (2007). The life-course origins of mastery among older people. Journal of Health and Social Behavior, 48, 164-179.

Pearlin, L. I., \& Schooler, C. (1978). The structure of coping. Journal of Health and Social Behavior, 19, 2-21. 
Polce-Lynch, M., Myers, B. J., Kliewer, W., \& Kilmartin, C. (2001). Adolescent self-esteem and gender: Exploring relations to sexual harassment, body image, media influence, and emotional expression. Journal of Youth and Adolescence, 30, 225-244.

Pomerantz, E. M., \& Ruble, D. N. (1998). The role of maternal control in the development of sex differences in child self-evaluation factors. Child Development, 69, 458-478.

Raley, S., \& Bianchi, S. (2006). Sons, daughters, and family processes: Does gender of children matter? Annual Review of Sociology, 32, 401-421.

Raudenbush, S. W., \& Bryk, A. S. (2002). Hierarchical linear models: Applications and data analysis methods. Thousand Oaks, CA: Sage.

Rushton, J. L., Forcier, M., \& Schectman, R. M. (2002). Epidemiology of depressive symptoms in the National Longitudinal Study of Adolescent Health. Journal of the American Academy of Child and Adolescent Psychiatry, 41, 199-205.

Ryan, R. M., \& Lynch, J. H. (1989). Emotional autonomy versus detachment: Revisiting the vicissitudes of adolescence and young adulthood. Child Development, 60, 340-356.

Siegel, J. M., Yancey, A. K., Aneshensel, C. S., \& Schuler, R. (1999). Body image, perceived pubertal timing, and adolescent mental health. Journal of Adolescent Health, $25,155-165$.

Singer, J. D. (1998). Using SAS PROC MIXED to fit multilevel models, hierarchical models, and individual growth models. Journal of Educational and Behavioral Sciences, 23, 323-355.

Steinberg, L. (1987). Family processes in adolescence: A developmental perspective. Family Therapy, 14, 77-86.

Thoits, P. A. (1991). On merging identity theory and stress research. Social Psychology Quarterly, 54, 101-112.

Turner, R. J., \& Avison, W. R. (2003). Status variations in stress exposure: Implications for the interpretation of research on race, socioeconomic status, and gender. Journal of Health and Social Behavior, 44, 488-505.

Turner, R. J., \& Lloyd, D. A. (1999). The stress process and the social distribution of depression. Journal of Health and Social Behavior, 40, 374-404.

Vredenburg, K., Krames, L., \& Flett, G. L. (1986). Sex differences in the clinical expression of depression. Sex Roles, 14, 37-49.

Ware, J. E., Johnson, S., Davis-Avery, A., \& Brook, R. (1979). Conceptualizations and measurement of health for adults in the health insurance study. Santa Monica: Rand Corporation.

Wenz-Gross, M., Siperstein, G. N., Untch, A. S., \& Widaman, K. F. (1997). Stress, social support, and adjustment of adolescents in middle school. The Journal of Early Adolescence, 17, 129-151.

Wichstrøm, L. (1999). The emergence of gender difference in depressed mood during adolescence: The role of intensified gender socialization. Developmental Psychology, 35, 232-245. 